Available Online at https://www.nepjol.info/index.php/IJOSH

International Journal of Occupational Safety and Health, Vol. 6 No. 2 (2016) $13-20$

\title{
Psychosocial factors associated with occupation: A comparative study between brick kiln and grocery workers
}

\author{
Seshananda Sanjel ${ }^{1}$, Sanjay N. Khanal ${ }^{2}$, Ajay Risal ${ }^{3}$, Steven M. Thygerson ${ }^{4}$, Sunil K. Joshi ${ }^{5}$ \\ ${ }^{1}$ Department of Community Medicine, Kathmandu University School of Medical Sciences, Dhulikhel Hospital, \\ Dhulikhel, Kavre, ${ }^{2}$ Department of Environment Science and Engineering, School of Science, Kathmandu \\ University, Dhulikhel, Nepal, ${ }^{3}$ Department of Psychiatry, Kathmandu University School of Medical Sciences, \\ Dhulikhel Hospital, Dhulikhel, Kavre, ${ }^{4}$ Department of Health Sciences, Brigham Young University, Provo, Utah, \\ USA, ${ }^{5}$ Department of Community Medicine, Kathmandu Medical College, Kathmandu University, Kathmandu, \\ Nepal
}

\section{ABSTRACT}

Background: Psychosocial factors, like physical, chemical and biological factors, are also the potential hazards. But, psychological factors, such as stress, are not mentioned in every kinds of occupation. Some important psychosocial manifestations found among the workers in previous studies were headache, depression, frustration, worry, low self-esteem, boredom and lack of sleep.

Objective: This study was carried out to evaluate and psychosocial factors that are associated with occupational factor between brick kiln workers and grocery workers

Methods: An analytical cross-sectional study was conducted in Kathmandu Valley during February-March 2015 i, targeting all the brick kiln workers. Firstly, all the registered the brick kilns (106 in number) were visited to form the potential sampling frame. Multi-stage probability proportionate to size sampling was applied to select 400 brick kiln workers from 16 brick kilns who had been working there for more than two years. An equal size unmatched reference group was maintained from the grocery workers. Interviews were conducted by trained health workers. Data was entered in the Microsoft (MS) excel and was transferred into the International Business Machines(IBM) Corporation. Statistical Package for the Social Sciences (SPSS) Statistics 21 was used to perform analysis. Both descriptive and (mean, median and inter-quartile range) and inferential (Mann Whitney $U$ test) statistics were computed. The level of significance was set at $<0.05$.

Results: Nearly $20.0 \%$ of exposed workers were $<19$ years of age among which slightly above three fifth achieved primary education. Almost $40 \%$ of brick kiln workers were ever smokers. Positive factors of psychosocial and emotional functioning were lower and negative factors were higher among brick kiln workers.

The parameters of relationships such as self-esteem, stress and personal agency and the parameters of emotions like emotional, somatic, chronic fear, anxiety, hopelessness, helplessness, abuse and mal-treatment were better and significantly better respectively, in the reference group than the exposed group. However, the social factor was significantly poor among the reference group i.e. the grocery workers as observed while conducting Mann Whitney $U$ test at $p<0.05$ level.

Conclusion: Among most of the parameters, brick kiln workers' psychosocial functioning was significantly poorer than the grocery workers. Providing formal and/or non-formal education as well as raising awareness about the deleterious effects of the exposure to brick kiln workers should be recommended.

Key words: brick kiln, emotional, grocery, Nepal, psychosocial functioning, relationship,

DOI: https://doi.org/10.3126/ijosh.v6i2.22527

\section{Corresponding Author}

Dr. Seshananda Sanjel

Department of Community Medicine, Kathmandu University School of Medical Sciences, Dhulikhel Hospital, Dhulikhel, Kavre

E-mail: seshanandasanjel24@gmail.com

(c) 2016 IJOSH All rights reserved

\section{Introduction}

uidelines on Occupational Safety and Health 3 Management Systems to assist organizations introducing occupational safety and health $(\mathrm{OSH})$, incorporated psychosocial factors as one of the potential hazards similar to the physical, chemical and biological factors.[1] Although, mental disturbances 
and musculoskeletal diseases form two main reasons for disability,[2]only the physical, chemical, biological and/or ergonomic factors were found to be seen as important.[1]Furthermore, in almost every occupation, psychological factors, for example stress, are not even mentioned.[3, 4]

Within brick kiln, green brick molding, green brick stacking, red brick loading, putting coal in the furnaces and coal preparation are the main activities.[5, 6] Brickfield tasks are labour intensive, low paid and severely exposed to hazards.[4, 7]The processes in brick kilns involve interaction of various factors like personal factors (fatigue, fitness, age and experience of the workers), circumstantial factors(work schedule and work load) and psychological factors( low esteem, stress and anxiety among workers), which contribute to affect work and working life.[8]Seasonal and unorganized works in brick kilns constitute long working hours,inadequate rest, low wages, job insecurity and bullying by superiors that contributes to various physiological and psychosocial stress, which in turn tends workers to various behavioral problems.[4, 9, 10]Headache (58.2\%), depression $(63.6 \%)$, frustration $(67.3 \%)$, worry $(41.8 \%)$, low selfesteem $(60.0 \%)$, boredom (34.6\%) and lack of sleep $(45.5 \%)$ are among the important psycho-behavioral manifestations presented by those workers.[9]Bonded labor continues to exist in agriculture, brick kilns, stonebreaking industry and domestic servitude in Nepal. [4, 11]Moreover, child workers have even more decreased mental status with lower self-esteem and are likely to experience more psychological and somatic stress leading to the development of anti-social or delinquent behavior.[4, 12]Therefore, keeping all of these facts under consideration, this study was conducted to evaluate the psychosocial factors associated with occupation between the brick kiln workers and the grocery workers.

\section{Methods}

Ethical approval for this study was obtained from the institutional review committee of Kathmandu University School of Medical Sciences (IRC-KUSMS), Dhulikhel. Participation in the study was voluntary and written consent was obtained from the brick kiln owners before collecting any data. Written consent (thumb print in case of illiterate interviewees) was obtained from each interviewee before interviews.

Ananalytical cross-sectional study was conducted during February-March of 2015 in Kathmandu Valley, that includes three densely populated districts (Kathmandu, Lalitpur and Bhaktpur) targeting all the brick kiln workers. There were 106 operating brick kilns in Kathmandu Valley at the time of interview. Among them, 62 brick kilns were in Bhakatpur, 26 in Lalitpur and 18 in Kathmandu district. Firstly, all those brick kilns were visited to form the potential sampling frame.

Multi-stage probability proportionate to size (PPS) sampling was applied to select brick kilns and brick kiln workers in which the probability of selection for a sampling unit is directly proportional to a size measured.[13, 14]In total, nine kilns from Bhaktapur, four from Lalitpur and three from Kathmandu district were selected. In total 400 brick kiln workers who had been working for more than two year were included in the study. An equal size of unmatched reference group was maintained from the grocery workers who had been working for more than two year in small and middle standard groceries, excluding large shopping malls and roadside huts. Interviews were conducted by trained health workers by making unannounced visits to brick kilns and groceries.

The workers whose job duties were similar within a production unit of a brick kiln plant were grouped in five groups and about 25 respondents were interviewed from a group. This process of grouping workers is called similar exposed groups (SEGs).[15, 16] Brick kiln SEGs are commonly classified as green brick molding zone (GBMZ), green brick stacking zone (GBSZ), red brick loading zone (RBLZ), coal preparation zone (CPZ) and firing zone (FZ). Such type of job classifications probably results in widely different stressors which can be compared.

Interview was done by administering a Nepali version of the field pre-tested questionnaire. For psychosocial functioning data, two types of questionnaires were used namely (1) relationships related and (2) emotions related. In relationships, there were five sets of questions (self-esteem, stress, personal agency, relationship, and supervision and training). The four options for the "relationships" were (1) 'never', (2) 'sometimes', (3) 'often' and (4) 'always'. In emotions, there were six sets of questions (emotional, somatic, chronic fear and anxiety, hopelessness and helplessness, social factors, and abuse and mal-treatment). The four scales for the emotions were (1) 'not at all', (2) 'a little', quite a bit' and (3) 'a lot'. 
Data was entered in the MS excel software and data analysis was performed using the International Business Machines(IBM) Corporation Statistical Package for the Social Sciences(SPSS) Statistics 21.Proportions, mean and range were calculated for socio-demographics (age, gender, marital status, schooling and duration of work). For the psychological functioning factors, mean, median as well as interquartile ranges were computed. The Mann Whitney $U$ test was applied to test significance between psychosocial functioning statuses of the study subject groups. The level of significance was set at $<0.05$ level.

\section{Results}

Questionnaire was completed by 800 participants [exposed: 400 and reference: 400]. Almost 20\% of exposed workers were less than 19 years of age, whereas only three percent of reference group were in this age group. The mean \pm SD age of exposed was $31.74 \pm 12.97$ years with range of 12 to 73 years and for reference was $33.33 \pm 9.03$ years with range of 14 to 68 years. Among those, $63 \%$ of brick workers achieved only primary education whereas almost $95 \%$ of grocery workers attained secondary and university education. Almost $40 \%$ of exposed and $35 \%$ of reference were ever smokers whereas $84.0 \%$ of exposed and $85.7 \%$ of reference were current smokers (Table 1).

See table 2 for the inter-quartile range of the relationship factors and table 3 for the inter-quartile range of the emotional factors of the study subjects.

While conducting Mann Whitney $U$ test, the parameters of relationships i.e. self-esteem, stress and personal agency were significantly better in reference group than the exposed group at $p<0.05$ level. Similarly, the parameters of emotions i.e. emotional, somatic, chronic fear and anxiety, hopelessness and helplessness and abuse and mal-treatment were significantly better, but the social factor was significantly poor among the reference group i.e. grocery workers at $p<0.05$ level (Table 4).

Table 1: Socio-demographics of exposed and reference participants

\begin{tabular}{|c|c|c|c|c|}
\hline \multirow{3}{*}{ Socio-economic variables } & \multicolumn{4}{|c|}{ Response groups } \\
\hline & \multicolumn{2}{|c|}{ Exposed } & \multicolumn{2}{|c|}{ Referent } \\
\hline & $\mathbf{n}$ & $\%$ & $\mathrm{n}$ & $\%$ \\
\hline \multicolumn{5}{|l|}{ Age group of the respondents } \\
\hline$\leq 19$ years & 81 & 20.2 & 12 & 3.0 \\
\hline $20-29$ years & 119 & 29.8 & 129 & 32.2 \\
\hline $30-39$ years & 84 & 21.0 & 166 & 41.5 \\
\hline $40-49$ years & 68 & 17.0 & 72 & 18.0 \\
\hline $50-59$ years & 33 & 8.2 & 16 & 4.0 \\
\hline $60-69$ years & 11 & 2.8 & 5 & 1.2 \\
\hline$\geq 70$ years & 4 & 1.0 & 0 & 0 \\
\hline Total & 400 & 100.0 & 400 & 100.0 \\
\hline \multicolumn{5}{|c|}{ Exposed: mean age $=31.74$ years, $S D$ of age $=12.97$ years, range of age $=12$ to 73 years } \\
\hline \multicolumn{5}{|c|}{ Control: mean age $=33.33$ years, $S D$ of age $=9.03$ years, range of age $=14$ to 68 years } \\
\hline \multicolumn{5}{|c|}{ Gender } \\
\hline Female & 102 & 25.5 & 130 & 32.5 \\
\hline Male & 298 & 74.5 & 270 & 67.5 \\
\hline Total & 400 & 100.0 & 400 & 100.0 \\
\hline \multicolumn{5}{|l|}{ Attainment of formal education } \\
\hline No & 238 & 59.5 & 30 & 7.5 \\
\hline Yes & 162 & 40.5 & 370 & 92.5 \\
\hline Total & 400 & 100.0 & 400 & 100.0 \\
\hline \multicolumn{5}{|l|}{ Levels of education } \\
\hline Primary & 102 & 63.0 & 16 & 4.3 \\
\hline Lower secondary & 43 & 26.5 & 76 & 20.5 \\
\hline Secondary and higher secondary & 14 & 8.6 & 203 & 54.9 \\
\hline University & 3 & 1.9 & 75 & 20.3 \\
\hline Total & 162 & 100.0 & 370 & 100.0 \\
\hline
\end{tabular}

International Journal of Occupational Safety and Health (IJOSH) 
Sanjel S et al.

Table 1 cont...

\section{Duration of work in years}

\begin{tabular}{lcccc}
$\leq 5$ years & 265 & 66.2 & 237 & 59.2 \\
$6-10$ years & 63 & 15.8 & 113 & 28.2 \\
$11-15$ years & 30 & 7.5 & 28 & 7.0 \\
$16-20$ years & 23 & 5.8 & 19 & 4.8 \\
$\geq 21$ years & 19 & 4.8 & 3 & 0.8 \\
Total & $\mathbf{4 0 0}$ & $\mathbf{1 0 0 . 0}$ & $\mathbf{4 0 0}$ & $\mathbf{1 0 0 . 0}$ \\
\hline
\end{tabular}

Table 2: Relationship factors among psychosocial functioning for the brick kiln and grocery workers

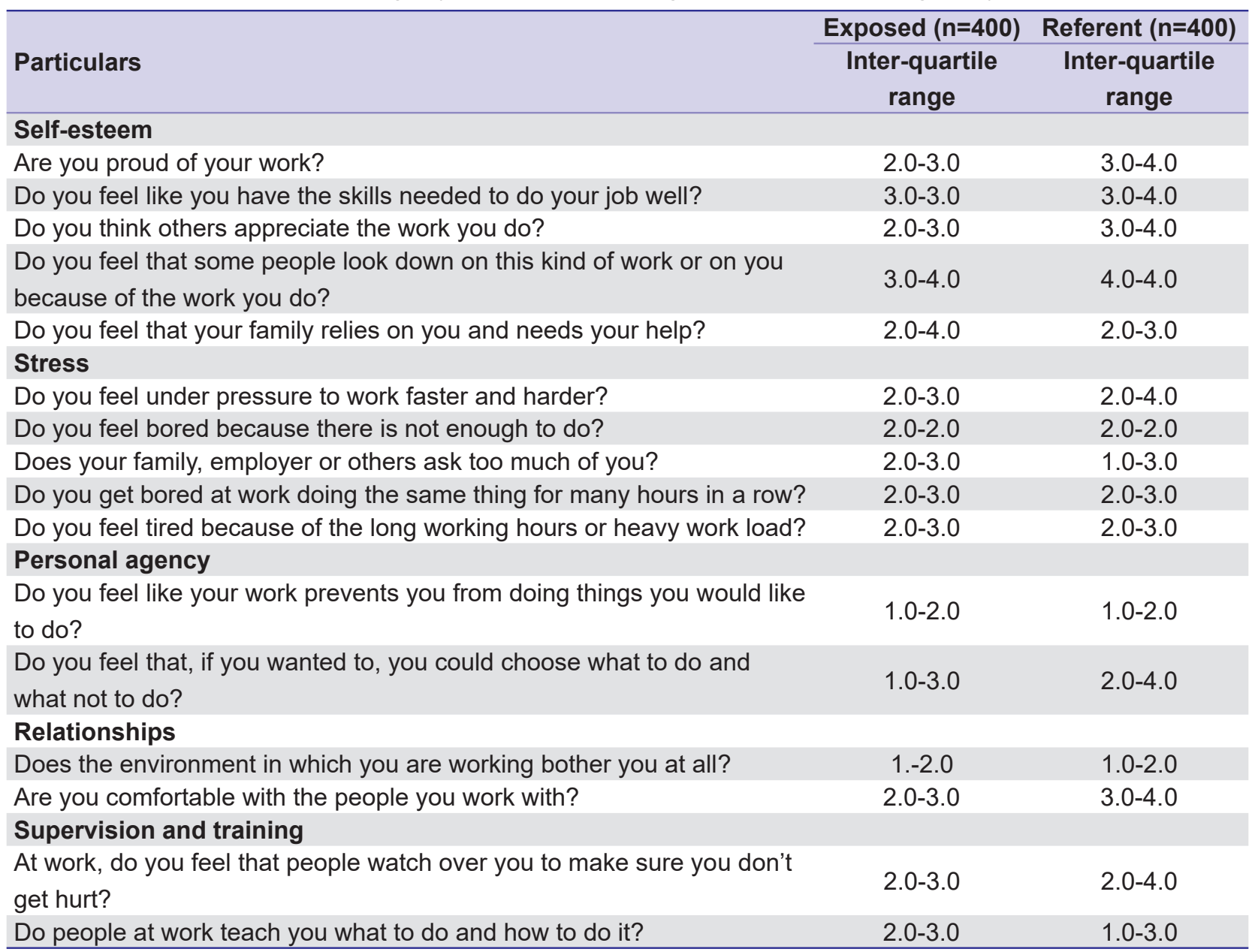

Table 3: Emotional factors among psychosocial functioning for the brick kiln and grocery workers

\begin{tabular}{lcc}
\hline Particulars & $\begin{array}{c}\text { Exposed }(\mathbf{n}=\mathbf{4 0 0}) \\
\text { Inter-quartile } \\
\text { range }\end{array}$ & $\begin{array}{c}\text { Referent }(\mathbf{n = 4 0 0}) \\
\text { Inter-quartile range }\end{array}$ \\
\hline Emotions & $3.0-4.0$ & $3.0-4.0$ \\
Do you have lots of energy? & $2.0-3.0$ & $3.0-4.0$ \\
\hline Do you generally feel pretty confident? & $3.0-4.0$ & $4.0-4.0$ \\
Do you have any difficulty sleeping? & $3.0-4.0$ & $3.0-4.0$ \\
Do you have trouble concentrating? & $3.0-4.0$ & $3.0-4.0$ \\
Do you feel restless and cannot stay still very long? & $3.0-4.0$ & $3.0-4.0$ \\
Do you feel sad and like crying? & $3.0-4.0$ & $4.0-4.0$ \\
Do you get into fights or quarrels easily? & $4.0-4.0$ & $4.0-4.0$ \\
Do you feel lonely? & $3.0-4.0$ & $4.0-4.0$ \\
Do you get very angry and often lose your temper? & $3.0-4.0$ & $3.0-4.0$
\end{tabular}


Table 3 cont...

Do you have little appetite or interest in food?

$\begin{array}{ll}3.0-4.0 & 3.0-4.0 \\ 3.0-4.0 & 3.0-4.0 \\ & \\ 2.0-4.0 & 3.0-4.0 \\ 2.0-4.0 & 3.0-4.0 \\ 3.0-4.0 & 3.0-4.0 \\ 3.0-4.0 & 3.0-4.0 \\ 4.0-4.0 & 4.0-4.0\end{array}$

Do you find that you forget things?

Somatic

Do you feel tension in your body?

Do you feel dizzy?

Chronic fear and anxiety

Do you feel afraid or nervous?

$4.0-4.0-4.0-4.0$

you?

\begin{tabular}{ll}
$2.0-4.0$ & $3.0-4.0$ \\
$3.0-4.0$ & $4.0-4.0$ \\
$4.0-4.0$ & $4.0-4.0$ \\
& \\
$3.0-4.0$ & $4.0-4.0$ \\
$3.0-4.0$ & $3.0-4.0$ \\
$2.0-3.0$ & $3.0-4.0$ \\
$2.0-3.0$ & $3.0-4.0$ \\
$4.0-4.0$ & $4.0-4.0$ \\
$1.0-2.0$ & $2.0-3.0$ \\
$3.0-4.0$ & $3.0-4.0$ \\
& \\
\hline $4.0-4.0$ & $4.0-4.0$ \\
$4.0-4.0$ & $4.0-4.0$ \\
$4.0-4.0$ & $4.0-4.0$ \\
$4.0-4.0$ & $4.0-4.0$ \\
$3.0-3.0$ & $3.0-4.0$
\end{tabular}

Do you think your life will get better some day?

Do you think your life is worse than that of other workers?

Do you think life isn't worth living?

Social factors

Do you feel supported and loved by your family?

Is there conflict in your family?

Do you feel accepted by the other families around here?

Do you have one or more good friends that support you?

Do people reject or tease you or call you names?

Do you play games or sports with friends?

our age?

Abuse and maltreatment

Do you get scolded, or criticized or made to feel small or stupid?

Do you get beaten at home or work?

Has anyone at work tried to touch you in a bad way?

$3.0-4.0$

4.0-4.0

$0-4.0$

Have you been severely punished for mistakes made at your work?

In your day-to-day life do you feel safe?

Table 4: Mann Whitney $U$ test for psychosocial functioning status between exposed and reference groups

\begin{tabular}{|c|c|c|c|c|c|c|c|}
\hline \multirow[b]{2}{*}{ Parameters } & \multicolumn{2}{|c|}{ Exposed $(n=400)$} & \multirow[b]{2}{*}{$\begin{array}{l}\text { Inter-quartile } \\
\text { range }\end{array}$} & \multicolumn{3}{|c|}{ Reference $(n=400)$} & \multirow[b]{2}{*}{$P$ value } \\
\hline & Mean & Median & & Mean & Median & $\begin{array}{c}\text { Inter-quartile } \\
\text { range }\end{array}$ & \\
\hline \multicolumn{8}{|l|}{ Psychosocial factors } \\
\hline Self-esteem & 14.9 & 15.0 & $13.0-17.0$ & 16.4 & 16.0 & $15.0-18.0$ & $<0.001$ \\
\hline Stress & 12.1 & 12.0 & $11.0-13.0$ & 11.5 & 12.0 & $10.0-13.0$ & 0.046 \\
\hline Personal agency & 3.7 & 4.0 & $3.0-5.0$ & 4.2 & 4.0 & $3.0-5.0$ & $<0.001$ \\
\hline Relationship & 4.6 & 5.0 & $4.0-5.0$ & 4.4 & 5.0 & $4.0-5.0$ & 0.410 \\
\hline Supervision and training & 5.0 & 5.0 & $4.0-6.0$ & 4.9 & 5.0 & $4.0-6.0$ & 0.939 \\
\hline \multicolumn{8}{|l|}{ Emotional factors } \\
\hline Emotional & 36.6 & 37.0 & $34.0-39.0$ & 38.9 & 39.0 & $37.0-41.0$ & $<0.001$ \\
\hline Somatic & 6.0 & 6.0 & $5.0-7.0$ & 6.7 & 7.0 & $6.0-8.0$ & $<0.001$ \\
\hline Chronic fear and anxiety & 10.3 & 11.0 & $10.0-11.0$ & 10.7 & 11.0 & $10.0-12.0$ & 0.002 \\
\hline $\begin{array}{l}\text { Hopelessness and } \\
\text { helplessness }\end{array}$ & 9.3 & 9.0 & $9.0-10.0$ & 10.6 & 11.0 & $10.0-12.0$ & $<0.001$ \\
\hline Social factors & 20.8 & 21.0 & $19.0-22.0$ & 22.9 & 19.0 & $17.0-19.0$ & $<0.001$ \\
\hline Abuse and mal-treatment & 18.5 & 19.0 & $17.0-19.0$ & 19.2 & 19.0 & $19.0-20.0$ & $<0.001$ \\
\hline
\end{tabular}

\section{Discussion}

It is crucial that about one fifth of brick kiln workers were $<19$ years of age, whereas only three percent of grocery workers were in this age group. This signifies that child labor is hugely prevalent in brick kilns. Among educated workers, slightly above three fifth of the brick kiln workers achieved only primary education. More illiterate people were engaged in the brick kilns 
with adoption of risky behaviors such as smoking, not using mask during work in the dusty work sites etc.

Many factors influence health, health service and community welfare; physiological and psychological makeup of the individual, as well as the structures and functions of society, form the two important aspects. Social characteristics such as patterns of interaction within family or occupational groups; cultural features such as traditional ways of solving conflicts; and the psychological determinants such as attitudes, beliefs and personality factors, play vital roles.[17]Among the physical characteristics, introduction of potentially harmful substances like gases and particulate matter from modern industrial civilization are known to have a tremendous negative and harmful impact on living organisms and human health.[18] There are multiple risk factors and illnesses that are directly related with the biomechanical, psychosocial, nutritional, clinical and respiratory ailments, which ultimately effect psychosocial functioning.[9]

In our current study, we focused mainly on the psychosocial factors related with the occupation having high exposures to pollution. The three parameters of relationships (self-esteem, stress and personal agency) were significantly better in reference group than the exposed group as shown by Mann Whitney $U$ test, and the all the five parameters of emotions (emotional, somatic, chronic fear and anxiety, hopelessness and helplessness and abuse and mal-treatment) were also significantly better among the reference group, but the social factor is significantly better among the exposed group i.e. brick kiln workers. Long working hours without adequate rest, low wages, job insecurity and bullying by superiors probably contributes to these psychosocial stressors. Both physiological and psychosocial stress tends workers to various addictive behaviors like smoking, chewing tobacco etc.[9, 19]Psychosocial risk factors effect health and functioning through stress mediated pathway. Chronic stress predisposes individuals to psychiatric illnesses like anxiety, depression and substance abuse; both physiological as well as the socio-cultural factors being responsible for it .[1, 20]Among the two different groups of workers in this study, exposed and reference group i.e. brick kiln vs grocery workers, we found more favorable psychosocial functioning in the grocery workers. They were more educated, earned more, had more leisure time and less stressed.[21, 22]Exposure to more pollutants may be the most important underlying mechanism for psychological distress among brick-kiln workers owing to their fear of working in the highly polluted workplace.[5]

Stress predisposes individuals to somatic symptoms, mainly chronic headache.[23, 24]Furthermore, chronic headaches are found to be comorbid with common mental disorders like anxiety and depression.[25]The common mental disorders are also seen more among the poor, illiterate, low socio-economic status, as well as those with poor physical health condition,[22]hence, our findings have major implication which indicated that psychosocial factors should not be neglected while studying occupational health status of the workers. Brick kiln workers are not only poor, marginalized, uneducated but also unhealthy; physically as well as psychologically. However, a few of them have given their effort to identify psychosocial issues.[26]Mental health status was related to functional limitation which suggested that improving function in this population may require: (1) pain coping techniques and active problem solving strategies to overcome functional barriers, and (2) reduction of workplace ergonomic risk exposure.[1, 27]

We have made our effort to dig into the issues discernable to other researchers, public health policy makers and the health planners.

Although we conducted the study utilizing the scientific rigors, there were shortcomings that could not be controlled. The baseline and end line study could not be carried due to the time and resource constraints. Furthermore, during searching the literature, very limited literatures were accessed that enormously impacted the discussion section of the study. Additionally, both the comparison groups selected for this study were not from the similar types of occupation, due to unavailability of similar types of industries in the study area which may have remarkably influenced the findings and interpretations of the study.

Our experiences in this study propose considering some future research paths while conducting any research. Future studies should be conducted by utilizing other standardized tools which will maintain researchers in the ease by accessing plenty of literatures. Moreover, the occupational groups from similar types of industries should be selected in order to increase the generalizability of the research. 


\section{Conclusion}

Brick kiln workers' psychosocial functioning was significantly poorer than the grocery workers in most of the parameters of psychosocial functioning.

Providing formal and/or non-formal education is crucial in order to make the workers know about the poor occupational environmental conditions of brick kilns Awareness on the deleterious effects of the exposure to brick kiln work hazards is recommended so as to protect health of workers that might help to prevent further worsening of psychosocial conditions of the workers. Further researches and studies utilizing other validated tools is also recommended.

\section{References}

1. ILO. Guidelines on occupational safety and health management systems. Geneva; 2001. Available from:https://www.ilo.org/global/publications/ilobookstore/order...EN/.../index.htm

2. Sjögren-Rönkä $T$, Ojanen $M T$, Leskinen EK, Mustalampi ST, Mälkiä EA. Physical and psychosocial prerequisites of functioning in relation to work ability and general subjective well-being among office workers. Scand J Work Environ Health. 2002;28(3):184-90. DOI: https://doi.org/10.5271/ sjweh.663

3. Huerta-Franco MR, Vargas-Luna M, Tienda $P$, Delgadilo-Holtfort I, Balleza-Ordaz M, FloresHernandez. Effects of occupational stress on the gastrointestinal tract. World Journal of Gastrointestinal pathophysiology. 2013;4(4). DOI: https://doi.org/10.4291/wjgp.v4.i4.108

4. Sanjel S, Thygerson SM, Khanal SN, Joshi SK. Environmental and Occupational Pollutants and Their Effects on Health among Brick Kiln Workers. Open J Safety Science Techno 2016;6(04):81-98. DOI: https://doi.org/10.4236/ojsst.2016.64008

5. Murthy VK, Khanal SN, Giri D. Occupational health and safety study (OHSS) of brick industry in the Kathmandu valley report. Dhulikhel, Kavre: Kathmandu University; 2007.

6. Joshi SK. Occupational Health and Safety Assessment of Child Workers in the Brick Industry, Nepal. Kathmandu, Nepal: World Education \& Kathmandu Medical college; 2013.

7. Bhukuth A. Child labour and debt bondage: A case study of brick kiln workers in Southeast India. Journal of Asian and African studies. 2005;40(4):287-302. DOI: https://doi.org/10.1177/0021909605055776

8. Qutubuddin SM, Hebbal SS, Kuma CS. Ergonomic Evaluation of Tasks Performed by Workers in Manual Brick Kilns in Karnataka, India. Global Journals Inc (USA). 2013;13(4):34-42.

9. Bandyopadhyay B, Sen D. Occupational Stress among Women Molders:A Study in Manual Brick Manufacturing Industry of West Bangel. Int J Scientific Re Public 2014;4(6):1-7.

10. Balu A. Growth of Unorganised Sector in India. Nanganallur, Chennai-600114, India. Availablefrom: https://www.researchgate.net/profile/Balu_Anthony/

publication/280443507_Growth_of_Unorganised Sector_in_India/links/55b4bb5d08aec0e5f4364714/ Growth-of-Unorganised-Sector-in-India.pdf

11. Grabs Educational Charitable Trust, 21/12, 8th Street, Bakthavachalam Nagar; 2014.Available from: https://yellowpages.webindia123.com/d-t/TamilNadu/Chennai/GRABS-Educational-CharitableTrust/62818/

12. Stallard R. Child trafficking in Nepal: Cause and consequencies; 2015.Available from: http://www. childreachtz.org/sites/default/files/imce/Child $\% 20$ Trafficking $\% 20 \mathrm{Nepal}-$ Causes $\% 20$ and $\% 20$ Consequences.pdf.

13. Pellenq C, Gunn S, Graves J, Ali MV. Mental health of child workers: Result from case-control study of the brick manufacturing industry in four countries. APHA 142nd Annual Meeting \& Expo; New Orleans, LA: Americal Public Health Association; 2014.

14. Turner AG. Sampling strategies: Handbook on Designing of Household Sample Surveys Geneva: United Nations Secretariat: Statistics Division; 2003. Available from: https://unstats.un.org/unsd/ demographic/meetings/egm/sampling_1203/docs/ no_2.pdf

15. EncyclopediaofSurveyResearchMethods. Probability Proportional to Size (PPS) Sampling. In: Lavrakas PJ, editor. Sampling: SAGE Reaearchmethods; 2008. Available from: methods. sagepub.com/reference/encyclopedia-of-surveyresearch.../n405.xml

16. Ghasemkhani M, Kumashiro M, Rezaei M, Anvari AR, Mazloumi A, Sadeghipour HR. Prevalence of Respiratory Symptoms among Workers in Industries of South Tehran, Iran. Industrial Health. 2006.;44:218-24. DOI: https://doi.org/10.2486/ indhealth.44.218

17. Spear JE. Industrial Hygiene Exposure Assessments: Worst-Case Versus Random Sampling2004: Available from: www.jespear.com/articles/04-07worstcase-vs-random.pdf.

18. WHO, editor. Occupational health: A manual for primary health care workers. Cairo, Egypt: World Health Organization, Regional Office for the Estern Mediterranean; 2001. Available from: https:// www.who.int/occupational_health/regions/en/ oehemhealthcareworkers.pdf 
19. Fatima I. Impact of Brick Kiln Emissions on the Ambient Air Quality and Vegetation: A Case Study of District Budgam. Srinagar-190006, India: The University of Kashmir, 2011.Available from: http:// dspaces.uok.edu.in:8080/jspui/bitstream/1/1007/1/ Irm\%20Fatima, \%202011\%20(M.Phil. \% 20 Dissertation).pdf.

20. Checkoway H, Heyer NJ, Demers PA, Breslow NE. Mortality among Workers in the Diatomaceous Earth Industry. British J Indus Med 1993;50:586-97. DOI: https://doi.org/10.1136/oem.50.7.586

21. Meijer E, Kromhout H, Heederik D. Respiratory Effects of Exposure to Low Levels of Concrete Dust Containing Crystalline Silica. Am J Ind Med 2001;40:133-40. DOI: https://doi.org/10.1002/ ajim.1080

22. Banibrata Das B. Assessment of Occupational Health Problems and Physiological Stress among the Brick Field Workers of West Bengal, India IJOMEH. 2014;27(3):413-25.

23. Ade-Oshifogun JB. Model of Functional Performance in Obese Elderly People with Chronic
Obstructive Pulmonary Disease. J Nur Scholar. 2012;44(3):232-41. DOI: https://doi.org/10.1111/ j.1547-5069.2012.01457.x

24. Cherry NM, Burgess GL, Turner S, McDonald LC. Crystalline silica and risk of lung cancer in the Potteries. Occup Environ Med 1998;55 779-85. DOI: https://doi.org/10.1136/oem.55.11.779

25. Helsing KJ, Comstock JW, Speizer FE, Ferris BG, Lebowitz MD, Tockman MS, et al. Comparison of Three Standardized Questionnaires on Respiratory Symptoms. American Review of Respiratory Disease 1979;120:1221-30.

26. Lumen Mieke EGL, Ton S. Determinants of Exposure to Respirable Quartz Dust in the Construction Industry. Ann occup Hyg 2001;45(7):585-95. DOI: https://doi.org/10.1016/S0003-4878(01)00025-4

27. ILO. Buried In Bricks: A Rapid Assessment of Bonded Labour in Afghan Brick Kilns2011.

28. Rastogi SK. Enironmental factors and physiological strain in workers employed in brick kilns. Indian Journal of Occupational and Environmental Medicine. 2002;6(2):66-70. 